\title{
Quality assurance of higher education in chemistry in Russia taking into account international trends in the context of the cognitive paradigm
}

\author{
Alsu Kamaleeva ${ }^{1}$, Suriya Gilmanshina ${ }^{2}$ \\ ${ }^{1}$ Institute of Pedagogy, Psychology and Social Problems, Isaeva st., 12, 420038 Kazan, Russia \\ ${ }^{2}$ Kazan Federal University, Kremlyovskaya st., 18, 420008 Kazan, Russia
}

\begin{abstract}
In the process of organizing chemistry education, it is important to understand that in the context of the introduction of the cognitive paradigm of education under the conditions of modern generating of chemical knowledge, the system of additional education as a universal form of development leads each student to a new, better state. Within the framework of a new approach to the organization of a purposeful process of teaching and upbringing by means of providing educational services by the implementation of additional educational programs, information and educational activities outside the main educational programs in the interests of students on the basis of the Kazan Federal University, author's electronic educational resources and digitized programs of additional education were developed and tested on the example of theoretical and experimental teaching at the Small Chemical Institute of the University. A survey of chemistry teachers working in schools in the city of Kazan or the Republic of Tatarstan, as well as graduates - future chemistry teachers showed that $97 \%$ of respondents use the possibilities of the system of additional chemistry education. The structure and logic of the implementation of the proposed programs expand the ability to use logical thinking operations in teaching, such as synthesis, analysis, analogy, comparison, generalization and systematization, and are aimed at forming students' understanding of a single chemical picture of the world, its materiality and the reasons for the diversity of the natural science world.
\end{abstract}

\section{Introduction}

The relevance of the article lies in the fact that at the moment the Russian system of additional education is becoming increasingly important in the upbringing and development of the younger generation. Natural science [1] and engineering education [2, 3] are of particular interest. Accordingly, the need for qualified personnel in an educational institution is also increasing, who will be able to organize and implement projects related to additional chemical education for students. The teacher must have a certain research and methodological base in this area in order to ensure the qualitative growth of the educational and methodological support of the taught discipline. 
Article 2 of the Federal Law of December 29, 2012 No. 273-FZ (as amended on April $24,2020)$ "On education in the Russian Federation" emphasizes that additional education is a type of education aimed at fully satisfying the educational needs of a person in intellectual, spiritual, moral, physical or professional improvement and is not accompanied by an increase in the level of education [4].

A study of federal documents describing additional education helped to identify a number of problems in the legal regulation, namely:

- The problem of qualified personnel in the areas of additional education for students, a significant lack of material support of specialists in additional education;

- Impossibility to satisfy the social order of children due to a lack of personnel and underdevelopment of the material base;

- The lack of the possibility of widespread introduction of paid additional educational services due to the large number of families in Russia with low material wealth [5].

The solution of the problems presented above is especially significant due to the fact that the development of additional education effectively affects:

- Creation of a general cultural and emotional background for a positive understanding of the values of general education and successful assimilation of the content;

- Implementation of "unobtrusive" education - when students are included in creative, personally significant activities;

- The orientation of students who show great interest in certain types of activity, to realize their abilities in the institution of additional education for students [6].

Emotional saturation is another feature of the development of children in the context of organizing additional education. An emotional-value attitude towards the world can be formed in students in the process of communicating with outstanding personalities, whose work and creativity inspired them to seek answers to questions [7]. We agree with the authors of the textbook on additional education [8] that additional education is a purposeful process of teaching and upbringing by means of providing additional educational services, the implementation of additional educational programs and information and educational activities outside the main educational programs in the interests of the individual, the state [8].

Comparison of the parameters of organization and availability of additional education in different countries of the world is manifested, first of all, in the differences in approaches to defining the definition of "additional education". In English-speaking practice, there are different concepts that can be correlated with the Russian idea of additional education, such definitions as "outdoor education", "extracurricular activities", "supplementary education", "additional education", "education", "leisure", "extended education "," after school education" [9]. This is due to the fact that abroad the concept of "general" is understood as formal, which is inextricably linked with additional (non-formal) education [10].

Independent development and separation received additional education only in the nineteenth century. In Europe, there are two concepts of organizations that are outside the school - this is the concept of development and the concept of care, expressing the requirements for institutions of additional education [11].

The most progressive and successful in terms of the development of non-formal education is Western Europe [12]. In Western Europe, the concept of care is a pillar of continuing education institutions. The main focus of this concept is to help teenagers or children with very serious problems. This direction of development of institutions of additional education was chosen by Poland and the Netherlands. In addition to out-ofschool departments, they have foundations, associations and centers of non-formal education, Jordanian gardens, youth centers, youth palaces [13].

In Central and Eastern Europe, the concept of development is predominant. The state sponsors in the interests of a large group of young people who have no problems 
psychologically, socially or physically. The extracurricular system of leisure there demonstrates state support, and this explains mainly the official occupation of the bodies of additional education [14].

High expectations in the potential of additional education are also explained by the main international organizations OECD and UNICEF [15].

The Ministry of Education in Singapore defines four groups of additional circles communities and clubs, military-patriotic education, classes in subjects (for example, natural sciences or handicraft and cooking circles), physical education and sports, spectacular and visual arts [16].

The content of additional education in the United States is very diverse. Although, as follows from the website of the US Department of Education, they do not have an official name for areas in the system of additional education, they offer differentiation according to the main goal of the educational program, for example, circles in specialties (art, sports, theater, science or the scout movement), universal circles ( after-school groups, clubs for girls or boys); the purpose of studying in academic circles is to increase or increase academic success, "catch up" missed material or study super new programs. The greatest attention is paid to specialty circles [17].

Additional education in Australia covers a wide range of subjects from three main areas: musical and creative, sports and outdoor education [15].

If we consider additional chemical education abroad, then in this area China is considered to be successful, with a new education system (NSO). This system is focused on solving practical problems using scientific knowledge; it places great emphasis on maximizing the satisfaction of the craving for knowledge and maintaining enthusiasm in solving creative problems. For example, in organic chemistry, the following questions are asked: theoretical questions in organic chemistry; organic chemistry in everyday life; organic chemistry and medicine; organic chemistry in agricultural industry, high technology or military affairs [18].

The system of additional education for children of the Russian Federation in its new qualitative state has been implemented for more than 10 years [19]. The idea of transforming Russian education into an important factor in ensuring Russia's competitiveness among the developed countries of the world was taken as the leading one. This is recreated in state documents based on the implementation and development of the national project "Education" (dated 05.09.2005) [20], which should be implemented by December 31, 2024, as well as the National Educational Initiative "Our New School" (from 04.02.2010) [21].

The state assumes responsibility for the fact that in the near future the educational opportunities of citizens will be expanded and accessible. This is a necessity for the modern education market. If the sphere of educational services, which will be sponsored by the state, will increase, this will have a positive impact on the progressive development of competition in the global educational market.

Modern Russian additional education is implemented on the basis of the principles of democratization, humanization, personalization and pedagogy of cooperation in the context of the cognitive paradigm within the framework of a new direction in education "cognitive pedagogy", which transforms the processes of teaching and upbringing in the context of the formation of cognitive and personal structures of a person [22].

Thus, at the current level of development of society, the world pedagogical community realizes that any budgetary investment in the development of additional education is a longterm investment in the future development of society and the state. 


\section{Methods}

In accordance with the Regulation on an additional general educational general development program, the structure of additional programs must correspond to:

- A certain established level of education (primary, general, basic general, secondary general education);

- Cultural achievements in the world, as well as Russian traditions;

- The latest modern educational technologies, which are recreated in the principles of learning (accessibility, individuality, efficiency, continuity);

- Methods and forms of education (distance or differentiated learning, competitions, classes, competitions, excursions, etc.);

- Methods of management and control of the educational process;

- Teaching aids (a list of the necessary equipment, tools and materials, counting on the union of students) [23].

In chemistry, the theoretical part of the additional education program is, as a rule, modern ideas about the state of aggregation of substances, the quantitative and qualitative composition of substances, the basics of chemical analysis and chemical processes [24]. In addition to the above topics, there are also topics such as acquaintance with chemical household products, biochemistry, electrochemistry, chemistry of metals and non-metals, achievements in the field of chemistry in the national economy. A large amount of time is devoted specifically to issues of experimental chemistry, practical and laboratory work in the laboratories of a school or university.

Such a format and such a structure of the program of additional chemical education allow students to form ideas about a single chemical picture of the world, its materiality, the reasons for its diversity, and also enable students to master the chemical content well and understand the role of chemistry in the system of sciences about nature and biological processes. The structuring and logic of programs help to apply logical operations of thinking in teaching, such as synthesis, analysis, analogy, comparison, generalization and systematization. Indeed, the authors of the monograph "Cognitive Pedagogy: e-learning technologies in the professional development of a teacher" [25] note that in modern conditions of implementation in practice higher education, modern information and communication technologies, training programs that provide pedagogical interaction and feedback on its results, as external forms of organization of the learning environment and educational communication, "it is forgotten that these topics reflect only external forms of organization of the learning environment and educational communication, itself the essence of learning processes remains aside" [25]. They emphasize that, within the framework of cognitive didactics, the role of the teacher is to create conditions leading to the development of individual cognitive abilities and tools of human cognition, especially when it comes to the formation of a single picture of the world in students [26, 27].

In order to implement the national projects "Education" and "Science", the successful implementation of the Strategy for the scientific and technological development of Russia [22] and the implementation of early vocational guidance of students [28] within the framework of advanced training courses for chemistry teachers and the training of undergraduates with speciality 44.04.01. "Pedagogical education, profile - chemical education" on the basis of the Kazan Federal University were prepared and tested electronic educational resources "Improving the professional competencies of a chemistry teacher" (http://edu.kpfu.ru/course/view.php?id=1332) and "Educational practices with gifted students" (https://do.kpfu.ru/course/view.php?id=5313; theme 2), as well as digitized programs of additional education on the example of theoretical and experimental training at the Small Chemical Institute, who were successfully approbated with pupils of grades 8-11 of the IT-Lyceum and Lobachevsky Lyceum Kazan Federal University. 
The purpose of our study was to identify the attitude of chemistry teachers to the system of additional education and to solve the problem of maximum use of the information received in the process of building new programs of additional education in the process of training and advanced training of chemistry teachers on the use of digital technologies in the process of organizing extracurricular activities of students.

\section{Analysis of basic experimental data to ensure the quality of higher education in chemistry}

At the beginning of the 2020-2021 academic years, we conducted a survey of chemistry teachers in Kazan and the municipal districts of Tatarstan. A total of 120 teachers were interviewed. Of these, 68 teachers from rural schools, 28 from urban schools (11 of them are teaching in Kazan), as well as master's degree teachers -24 .

All answers were analyzed and ranked by teaching experience. Master's degree teachers studying at the Alexander Butlerov Institute of Chemistry at the Department of Chemical Education, entered the category of young teachers who have been working at school for no more than 5 years.

The first question about the employment period of the respondent made it possible to determine the percentage of teachers with different pedagogical experience and, accordingly, the opportunity to identify a pattern: does the acquired experience of work in school affect the teacher's attitude to the use of additional education technologies? Analysis of the results revealed that such a pattern is not observed.

However, to the question "Do they use extracurricular educational activities in chemistry in their professional activities?" $97 \%$ of teachers answered positively. If we consider the answers through the prism of work experience, then $84 \%$ of teachers with work experience of up to 5 years answered "yes", and $100 \%$ of teachers with work experience of 5 years or more answered that they use extracurricular activities in their work (Figure 1).

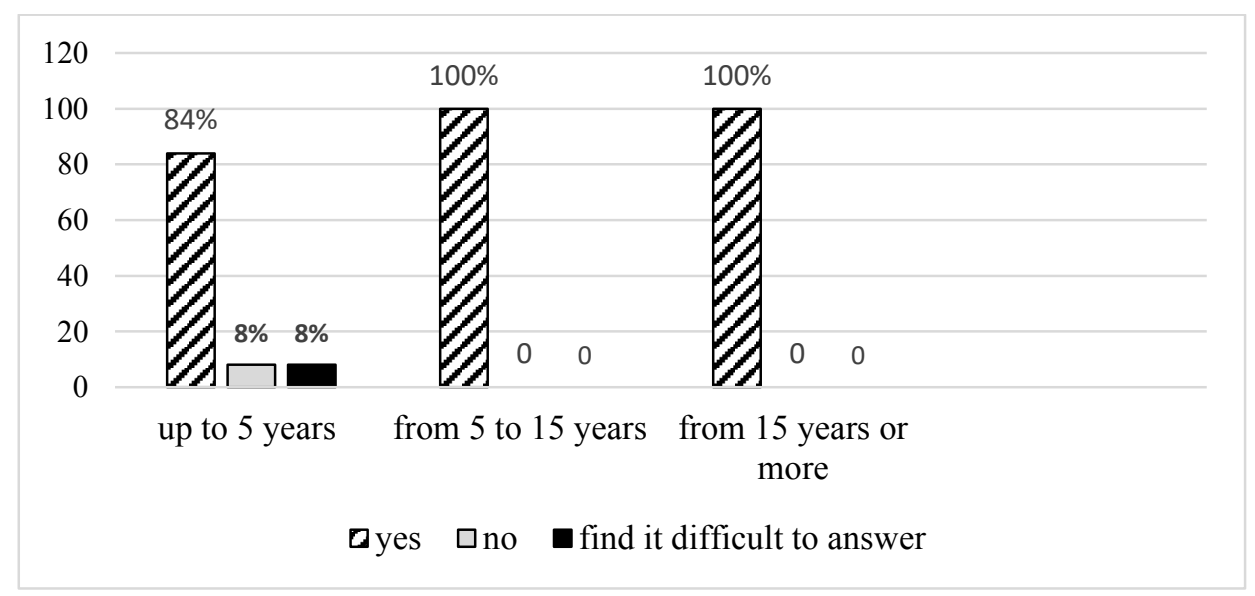

Fig.1. Do you use extracurricular educational activities in chemistry in your professional activities?

An analysis of the question of ways to search for information in the process of preparing a project for extracurricular educational activities in chemistry showed a slight difference between young teachers and teachers with work experience. Differences were revealed only in the use of the prevailing method of information retrieval (Fig. 2). 


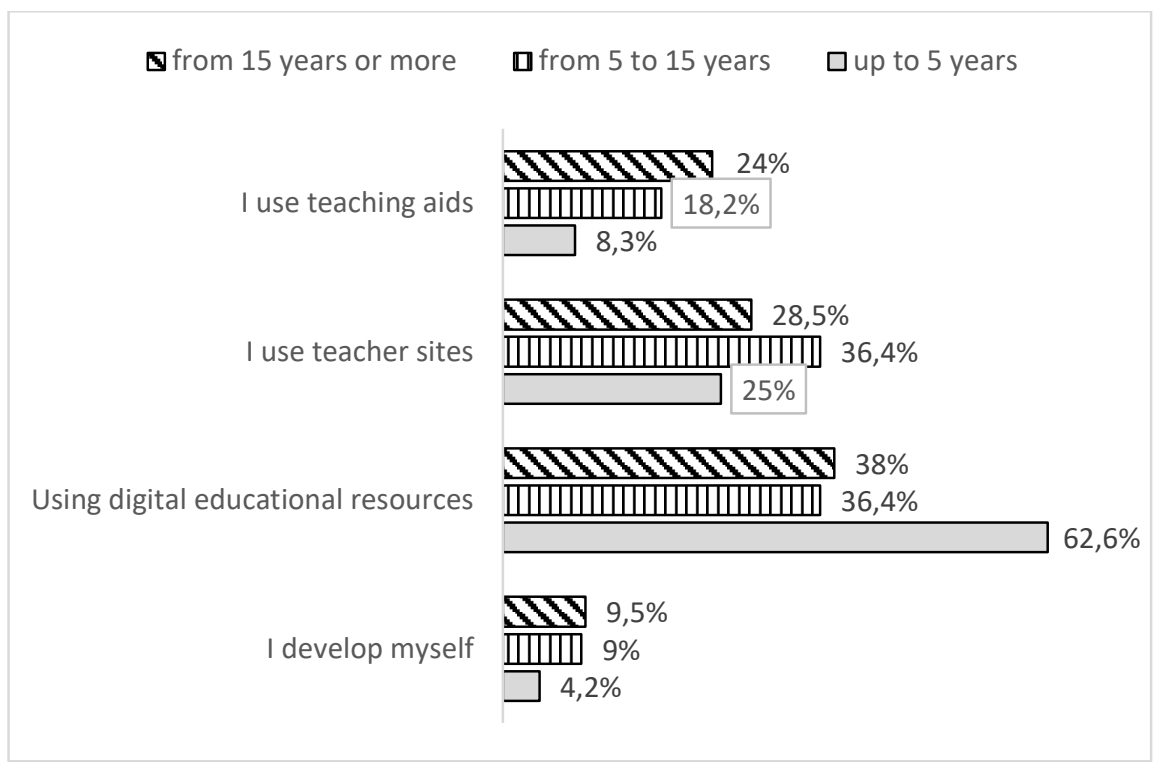

Fig.2. Where do you get information for extracurricular educational activities in chemistry?

Figure 2 show that all teachers prefer digital educational resources. These are $62.5 \%$ of respondents with experience of up to 5 years, $36.4 \%$ and $38 \%$, respectively, with experience of 5 to 15 and more than 15 years. Teachers' websites and teaching aids are more often used by teachers with work experience of 5 to 15 years; this is $36.4 \%$ and $18.2 \%$, respectively. A small number of teachers independently develop extracurricular activities: among undergraduates with work experience of up to 5 years, only 1 person, among teachers from 5 to 15 years -2 people and 7 teachers with work experience of more than 15 years.

The results of the survey also showed that many teachers use extracurricular activities in their teaching activities. When asked how often they organize educational activities in chemistry, $8.3 \%$ of respondents say that they do it once a week, $25 \%$ once a month, $46.6 \%$ every six months, $16.6 \%$ once a year and 3, 5\% do not carry out extracurricular activities at all. Thus, in general, teachers prefer to carry out extracurricular activities every six months (Fig. 3).

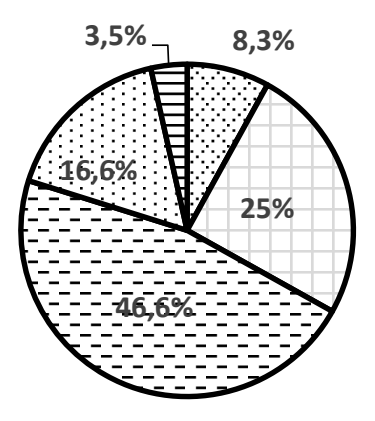
Donce a week
once a month
$\boldsymbol{G}$ once every six months
ⓞnce a year
口no events are held

Fig.3. How often do you conduct extracurricular educational activities in chemistry? 
We asked the same question to future chemistry teachers. The result can be seen in Figure 4, which shows that the majority chose the options "once a week" $-42.1 \%$, "once a month" $-47.4 \%$ and "once every six months" $-10.5 \%$. Moreover, the majority plans to conduct extracurricular activities once a month - this is $47.4 \%$ of the respondents. This may be due to the fact that future teachers often idealize their teaching activities, and teachers who have been working at school for a sufficient amount of time correctly assess their strength and time.

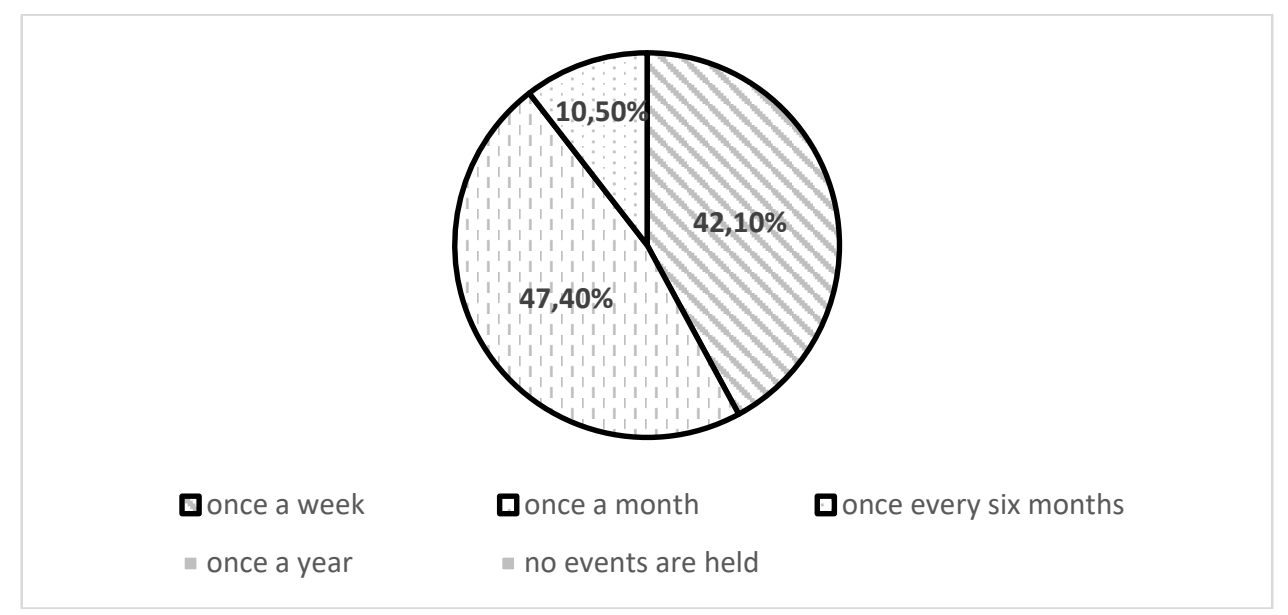

Fig.4. How often do you plan / want to conduct extracurricular educational activities in chemistry in the classroom?

In the course of the analysis of the experimental work, 120 teachers who directly work in schools in the city of Kazan or Tatarstan, as well as graduates - future chemistry teachers, were interviewed. The survey showed that work experience has little effect on the attitude and use of additional education in teaching. $97 \%$ of teachers conduct extracurricular activities with students, of whom the majority, and this is $46.6 \%$, conduct them every six months. Future teachers plan to conduct extracurricular activities once a month, $47.4 \%$ of students chose this option.

\section{Conclusions}

So, in the context of cognitive pedagogy, it can be stated that:

- in the current state of intensive knowledge generation, great importance is attached to the development of the system of additional education, in which special attention is paid to studying the process of individual acquisition and transformation of cognitive information by students;

- the use of the developed and tested structure of the program of additional chemical education in accordance with the Regulation on the additional developmental program allows students not only to firmly master the chemical content, but also to understand the role of chemistry in the system of sciences about nature and biological processes. This contributes to the formation of their idea of a single picture of the world, its materiality and the reasons for diversity. The structuring and logic of the implementation of programs help to apply in teaching logical operations of thinking, such as synthesis, analysis, analogy, comparison, generalization and systematization;

This study cannot claim to fully consider the complex and multifaceted problem of organizing additional chemical education in the context of intensive knowledge generation. 
The problems of cognitive modeling of conceptual, conceptual, procedural, structural and content characteristics of the organization of programs of additional chemical education seem to be important for further scientific research.

\section{References}

1. S.I. Gilmanshina, F. D. Khalikova, The European Proceedings of Social \& Behavioral Sciences, 12, 50 (2016).

2. I.R. Gilmanshin, S.I. Gilmanshina, IOP Conference Series: Materials Science and Engineering, 240, Art. 012022 (2017).

3. Y. Azimov, I. Gilmanshin, S. Gilmanshina, IOP Conference Series: Materials Science and Engineering, 134, Art. 012003 (2016).

4. Federal Law of December 29, 2012, No 273-FL (ed. from 27.12.2019) "Education in the Russian Federation".

5. Conceptual foundations of additional education. Systemic interaction of general and additional education to work with gifted children. Access mode: http://aracy.pф/files/documents/44-redaktor/kursy/pechenkina.pdf (access date: 12.05.2020).

6. Development programme of the supplementary education for children for 2012-2017. Access mode: https://shkola0419.ucoz.ru/ ld/3/355 _.pdf (access date: 23.05.2020).

7. Essence and specificity of additional education. Access mode: https://revolution.allbest.ru/pedagogics/00237313 0.html (access date: 22.05.2020).

8. E.B. Evladova, L.G. Loginova, N.N. Mikhailova, Supplementary education of children (Moscow, VLADOS, 2004).

9. S.G. Kosaretsky, M.E. Goshin, A.A. Belikov et al., Additional education of children in Russia: unified and diverse (Moscow, HSE, 2019).

10. T.V. Liskina, N.S. Paulsen, Bulletin of Baikal State University, 28 (1), 131 (2018).

11. A.V. Zolotareva, Yaroslavl Pedagogical Bulletin, 4, 46-53 (2015).

12. N.V. Ozhegova, Scientific Almanac, 5-2(19), 231 (2016).

13. V.V. Abraukhova, Innovative approaches in the activities of an institution of additional education as a means of its development (Rostov-on-Don, 1997).

14. N.M. Zhuljabina, Additional education of children abroad: understanding, politics, regulation (Moscow, NRU HSE, 2017).

15. International Standard Classification of Education 2011 (Montreal, Canada, UNESCO Institute for Statistics, 2013).

16. European education system. Access mode: https://bambinostory.com/evropeyskayasistema-obrazovaniya/ (access date: 12.03.2019).

17. D.S. Molokov, Yaroslavl Pedagogical Bulletin, 2(1), 225 (2013).

18. A bright thirtieth anniversary: a new stage in the development of education in China. Access mode: http://russian.china.org.cn/Sci-Edu-Cult/txt/200810/13/content 16605970.htm (access date: 25.09.2018).

19. The concept of modernization of additional education for children of the Russian Federation for the period up to 2020. Access mode: http://static.government.ru/media/files/ipA1NW42XOA.pdf (access date: 25.02.2019).

20. National project "Education". Access mode: https://edu.gov.ru/national-project (access date: 03.03.2019).

21. National educational initiative "Our new school". Access mode: http://uozato.ucoz.com/docs/nasha novaja_shkola.pdf (access date: 03.03.2019).

22. E. Levina, A. Kamaleeva, L. Mukhametzyanova, ARPHA Proceedings, 3, 1449-1464 (2020). 
23. Regulations on additional general educational developmental program. Access mode: http://ddt1.ru/wp-content/uploads/2018/05/Положение-о-дополнительнойобщеобразовательной-общеразвивающей-программе.pdf (access date: 13.04.2019).

24. Chemical Supplementary Education Programme. Access mode: https://pandia.ru/text/79/426/29693.php (access date: 20.05.2020).

25. S.F. Sergeev, M.E. Bershadsky, O. M. Chorosova et al., Cognitive pedagogy: elearning technologies in teacher professional development (Yakutsk, Russia, 2016).

26. S.F. Sergeev, Educational technologies, 4, 28 (2010).

27. A.R. Kamaleeva, L.Yu. Mukhametzyanova, N.A. Nozdrina, Science and Technology, 1, 102 (2019).

28. S.I. Gilmanshina, R.N. Sagitova, I.R. Gilmanshin, A.R. Kamaleeva, IOP Conference Series: Materials Science and Engineering, 240, Art. 012023 (2017). 